\title{
Desain Modul Pembelajaran Mandiri Tentang Gerak Parabola Pada Bidang Miring Tanpa Gesekan Udara
}

\author{
Beta Sugesti Situmeang ${ }^{1}$, Debora Natalia Sudjito ${ }^{1 *}$, Nur Aji Wibowo ${ }^{2}$ \\ 1Program Studi Pendidikan Fisika, Universitas Kristen Satya Wacana, Salatiga, 50711, Indonesia \\ ${ }^{2}$ Program Studi Fisika, Universitas Kristen Satya Wacana, Salatiga, 50711, Indonesia \\ *email: debora.natalia@staff.uksw.edu
}

Article Info: Submitted: 02/01/2019 | Revised: 02/02/2019 | Accepted: 24/02/2019

\begin{abstract}
Intisari - Pembelajaran tentang gerak parabola pada bidang miring tanpa gesekan udara pada umumnya tidak bisa disampaikan pada jam tatap muka karena waktu yang terbatas. Salah satu cara yang bisa ditempuh adalah materi gerak parabola di bidang miring tanpa gesekan dipelajari secara mandiri dengan bantuan modul pembelajaran mandiri. Tujuan penelitian ini adalah membuat desain modul pembelajaran mandiri tentang gerak parabola pada miring tanpa gesekan udara dan menyelidiki efektivitas modul pembelajaran mandiri tentang gerak parabola pada bidang miring terhadap pemahaman mahasiswa. Penelitian ini bermanfaat untuk memperkaya modul mekanika bagi mahasiswa dan membantu mahasiswa mempelajari materi gerak parabola pada bidang miring melalui pembelajaran mandiri yang bisa dilakukan di luar jam tatap muka sehingga pembelajaran gerak parabola dapat dipelajari secara komperehensif. Metode penelitian ini adalah metode pengembangan model ADDIE yang terdiri dari tahap Analysis (Analisis), Design (Desain), Development (Pengembangan), Implementation (Implementasi), dan Evaluation (Evaluasi). Modul pembelajaran mandiri ini diaplikasikan kepada tiga mahasiswa Fisika dan Pendidikan Fisika tingkat pertama. Berdasarkan hasil penelitian diperoleh dari lembar observasi, mahasiswa dapat mengerjakan 88\% langkah di modul dengan benar, mahasiswa memberikan 90\% tanggapan positif terhadap modul di kuesioner, dan semua mahasiswa memperoleh rata-rata nilai evaluasi sebesar 75. Jadi modul pembelajaran mandiri yang dibuat efektif dalam membantu mahasiswa memahami materi gerak parabola pada bidang miring tanpa gesekan udara.
\end{abstract}

Kata kunci: Modul pembelajaran mandiri, Gerak parabola, Bidang miring, Tanpa gesekan udara, ADDIE.

\begin{abstract}
Generally, the learning about projectile motion on inclined surface neglecting air friction can not be delivered during the meeting hours because of the limited time. One way that can be done is by doing independent learning about projectile motion on inclined surface neglecting air friction which is assisted by an independent learning module. The purpose of this study is to design an independent learning module of projectile motion on inclined surface neglecting air friction and to investigate the effectiveness of the module toward undergraduate student's understanding. Hopefully, this module can enrich the mechanics modules for the undergraduate students and support them in learning about projectile motion on the inclined surface out of the meeting hours so that they can learn about the projectile motion comprehensively. The method of this study is the ADDIE model of development method consisting of Analysis, Design, Development, Implementation, and Evaluation steps. This independent learning module is applied to three freshmen of the Physics and Physics Education Department. Based on the observation sheet, the undergraduate students were able to do $88 \%$ of the module correctly, they also give $90 \%$ positive response to the statements of the module, and gets an average evaluation score of 75. Therefore, this independent learning module about projectile motion on inclined surface neglecting air friction is effective in assisting undergraduate students in understanding the projectile motion on inclined surface neglecting air friction material.
\end{abstract}

Keywords: Independent learning module, Projectile motion, Inclined surface, Neglected air friction, ADDIE. 


\section{LATAR BELAKANG}

Selama ini pembelajaran fisika tentang gerak parabola biasanya hanya membahas gerak parabola pada bidang datar tanpa gesekan udara [1][2]. Padahal realitanya gerak parabola bisa terjadi pada bidang miring [3]. Pembelajaran tentang gerak parabola pada bidang miring tanpa gesekan udara pada umumnya tidak bisa disampaikan pada jam tatap muka karena waktu yang terbatas. Salah satu cara yang bisa ditempuh supaya mahasiswa dapat mempelajari materi gerak parabola di bidang miring tanpa gesekan udara adalah materi itu dipelajari secara mandiri oleh mahasiswa, misalnya sebagai tugas terstruktur perkuliahan mahasiswa. Oleh sebab itu, untuk membantu mahasiswa memahami secara mendalam gerak parabola pada bidang miring tanpa gesekan udara diperlukan modul pembelajaran untuk menuntun mahasiswa.

Modul pembelajaran mandiri dibuat karena beberapa penelitian yang telah dilakukan mengatakan bahwa modul pembelajaran mandiri efektif dalam membantu siswa untuk memahami konsep fisika [4][5]. Selain itu, sejauh ini belum ada buku atau modul yang membahas gerak parabola pada bidang miring tanpa gesekan udara secara spesifik sehingga penelitian ini dapat memperkaya referensi dan modul pembelajaran fisika, khususnya bagi perkuliahan mekanika di level mahasiswa[6].

Penelitian ini merupakan bagian dari penelitian tentang pembuatan modul pembelajaran mandiri tentang gerak parabola sebagai pembelajaran mandiri untuk level mahasiswa (S1). Modul gerak parabola ini membahas materi tentang (1) gerak parabola pada bidang datar tanpa gesekan udara, (2) gerak parabola pada bidang datar dengan gesekan udara, (3) gerak parabola pada bidang miring tanpa gesekan udara, dan (4) gerak parabola pada bidang miring dengan gesekan udara. Modul pembelajaran mandiri tentang gerak parabola pada bidang datar tanpa gesekan udara telah dibuat oleh [6], [7]. Penelitian lain yang serupa dengan topik fisika tentang optika telah dibuat oleh Dinavalentine (2016) [4] dan Astuti (2017) [5]. Modul yang dibuat pada penelitian ini adalah modul pembelajaran mandiri tentang gerak parabola pada bidang miring tanpa gesekan udara. Dalam gerak parabola pada bidang miring tanpa gesekan udara, beberapa besaran fisis yang dipelajari adalah [8][9]:
Vektor Percepatan :

$$
\overrightarrow{\mathbf{a}}=(-g \sin \gamma) \hat{\mathbf{i}}+(-g \cos \gamma) \hat{\mathbf{j}}
$$

Vektor Kecepatan :

$$
\overrightarrow{\mathbf{v}}=\left(\mathrm{v}_{0 \mathrm{x}}-g \sin \gamma \mathrm{t}\right) \hat{\mathbf{i}}+\left(\mathrm{v}_{0 \mathrm{y}}-g \cos \gamma \mathrm{t}\right) \hat{\mathbf{j}}
$$

Vektor Posisi [9] :

$$
\overrightarrow{\mathbf{r}}=\left(\mathrm{v}_{0 \mathrm{x}} \mathrm{t}-\frac{1}{2} g \sin \gamma \mathrm{t}^{2}\right) \hat{\mathbf{i}}+\left(\mathrm{v}_{0 \mathrm{y}} \mathrm{t}-\frac{1}{2} g \cos \gamma \mathrm{t}^{2}\right) \hat{\mathbf{j}}
$$

Tujuan penelitian ini adalah membuat desain modul pembelajaran mandiri tentang gerak parabola pada miring tanpa gesekan udara dan menyelidiki efektivitas modul pembelajaran mandiri tentang gerak parabola pada bidang miring terhadap pemahaman mahasiswa. Penelitian ini bermanfaat untuk memperkaya modul mekanika bagi mahasiswa dan membantu mahasiswa mempelajari materi gerak parabola pada bidang miring melalui pembelajaran mandiri yang bisa dilakukan di luar jam tatap muka sehingga pembelajaran gerak parabola dapat dipelajari secara komperehensif.

\section{METODOLOGI}

Pada penelitian ini digunakan metode pengembangan model ADDIE (Analysis, Design, Development, Implementation, Evaluation). Model ADDIE memiliki lima tahapan yaitu (1) Tahap Analysis. Tahap ini adalah dasar dari semua rencana yang dilakukan yaitu masalah yang ditemukan diidentifikasi dan dicari solusinya [10]; (2) Tahap Design. Desain dibuat berdasarkan analisis yang telah dilakukan dengan menguraikan bagaimana cara mencapai tujuan; (3) Tahap Development. Pada tahap ini dihasilkan bahan pembelajaran, misalnya simulasi atau peralatan [10][11]; (4) Tahap Implementasi. Output dari tahap pengembangan diterapkan dalam pembelajaran untuk mengetahui pengaruhnya terhadap kualitas pembelajaran yang meliputi efektivitas dan efisiensi pembelajaran; (5) Tahap Evaluation. Pada tahap ini data pada setiap tahapan dikumpulkan dan digunakan untuk penyempurnaan dan untuk mengetahui pengaruh desain yang dibuat terhadap efektivitas pembelajaran [11].

\subsection{Analysis (Analisis)}

Dalam pembelajaran mekanika pada tingkat mahasiswa, materi gerak parabola diajarkan sebatas 
bidang datar saja dan tanpa gesekan udara karena terbatasnya waktu perkuliahan tatap muka di kelas dan adanya idealisasi yaitu pengabaian gesekan udara untuk menyederhanakan perhitungan. Padahal gerak parabola tidak hanya terjadi pada bidang datar saja, realitanya gerak parabola bisa terjadi pada bidang miring juga. Untuk bisa mempelajari materi lebih mendalam mengenai gerak parabola pada bidang miring tanpa gesekan udara, diperlukan sebuah solusi. Solusi yang dipilih adalah dengan membuat sebuah modul pembelajaran mandiri tentang gerak parabola pada bidang miring tanpa gesekan udara berdasarkan modul pembelajaran tentang gerak parabola pada bidang datar tanpa gesekan udara yang dibuat oleh Karanggulimu [7]. Modul ini dibuat agar mahasiswa bisa belajar tanpa harus melakukan tatap muka di kelas.

\subsection{Design (Desain)}

Pada tahap ini, modul pembelajaran mandiri tentang gerak parabola pada bidang miring tanpa gesekan udara dibuat untuk level mahasiswa (S1) dan mengacu pada modul pembelajaran mandiri tentang gerak parabola pada bidang datar tanpa gesekan udara yang telah dibuat oleh Karanggulimu [7]. Modul pembelajaran mandiri ini berisi langkahlangkah pembelajaran yang memuat kalimat-kalimat informasi dan pertanyaan-pertanyaan penggiring yang menuntun mahasiswa untuk memahami konsep dan menemukan persamaan-persamaan yang terdapat pada gerak parabola di bidang miring tanpa gesekan udara.

Modul ini memuat delapan tujuan yaitu : mahasiswa dapat : (1) menggambarkan vektor gaya, percepatan, dan kecepatan di posisi tertentu benda, (2) menemukan persamaan percepatan benda $\left(\mathrm{a}_{\mathrm{x}}, \mathrm{a}_{\mathrm{y}}\right),(3)$ menemukan persamaan kecepatan benda $\left(v_{x}, v_{y}\right)(4)$ menemukan persamaan waktu saat benda mencapai titik tertinggi, (5) menemukan persamaan posisi $(x, y),(6)$ menemukan persamaan waktu saat benda mencapai titik terjauh, (7) menemukan persamaan posisi saat benda mencapai titik tertinggi, dan (8) menemukan persamaan posisi saat benda mencapai titik terjauh pada gerak parabola di bidang miring tanpa gesekan udara.

Selain modul pembelajaran mandiri, ada beberapa instrumen penelitian yang disiapkan, yaitu soal evaluasi, lembar observasi, dan lembar kuesioner. Modul pembelajaran digunakan untuk panduan mahasiswa memahami konsep materi. Soal evaluasi digunakan untuk mengetahui sejauh mana pemahaman mahasiswa terhadap gerak parabola pada bidang miring tanpa gesekan setelah menggunakan modul pembelajaran mandiri untuk belajar. Lembar observasi diisi oleh observer untuk merekam berlangsungnya kegiatan pembelajaran mandiri mahasiswa. Lembar kuesioner digunakan untuk mengetahui tanggapan mahasiswa terhadap modul pembelajaran mandiri setelah melakukan pembelajaran mandiri menggunakan modul yang dibuat, apakah modul membantu mereka memahami materi atau tidak dan menampung saran dari responden untuk memperbaiki modul pembelajaran.

\subsection{Development (Pengembangan)}

Pengembangan modul dilakukan melalui uji coba modul kepada beberapa mahasiswa. Dari hasil uji coba modul diperoleh kritik dan saran yang digunakan untuk memperbaiki modul, khususnya pada bagian kalimat informasi dan pertanyaan penggiring agar mudah dipahami oleh responden penelitian saat implementasi berlangsung.

\subsection{Implementation (Implementasi)}

Modul diberikan kepada para responden yaitu tiga mahasiswa Fisika dan Pendidikan Fisika tingkat pertama yang sudah mengambil mata kuliah mekanika. Pada tahap ini modul pembelajaran mandiri tentang gerak parabola pada bidang miring tanpa gesekan udara yang telah dibuat diberikan ke mahasiswa untuk dikerjakan. Selama mahasiswa mengerjakan modul, observer mengisi lembar observasi dan mendokumentasikan jalannya pembelajaran. Tidak ada siapapun yang boleh mengintervensi pembelajaran mandiri yang sedang dijalani oleh para responden. Setelah mahasiswa selesai mengerjakan modul, mahasiswa mengerjakan soal evaluasi dan mengisi lembar kuesioner.

\subsection{Evaluation (Evaluasi)}

Pada tahap evaluasi, semua data yang terkumpul dari soal evaluasi, lembar observasi, dan lembar kuesioner dianalisa dengan menggunakan metode deskriptif kualitatif. Modul pembelajaran mandiri tentang gerak parabola pada bidang miring tanpa gesekan udara dikatakan efektif membantu mahasiswa memahami materi gerak parabola pada 
Volume 12 Nomor 1, Bulan April, Tahun 2019, pp: 9 - 19

Available online at: http://jurnal.umpwr.ac.id/index.php/radiasi p-ISSN: $\underline{2302-6111}$ e-ISSN: $\underline{2549-0826}$

bidang miring tanpa gesekan udara jika (1) berdasarkan lembar observasi, semua responden dapat mengikuti/mengerjakan minimal $70 \%$ dari semua langkah di dalam modul pembelajaran mandiri dengan benar, (2) semua responden memberikan umpan balik positif berupa jawaban 'ya' berupa skala 3 (skor $75 \%$ ) atau 4 (skor $100 \%$ ) terhadap minimal $70 \%$ pertanyaan di kuesioner, dan (3) semua responden memperoleh nilai evaluasi minimal 70 dari nilai tertinggi 100 .

\section{HASIL DAN PEMBAHASAN}

Modul pembelajaran mandiri tentang gerak parabola pada bidang miring tanpa gesekan udara memuat delapan tujuan yaitu : mahasiswa dapat : (1) menggambarkan vektor gaya, percepatan, dan kecepatan di posisi tertentu benda, (2) smenemukan persamaan percepatan benda $\left(\mathbf{a}_{\mathbf{x}}, \mathbf{a}_{\mathbf{y}}\right)$, (3) menemukan persamaan kecepatan benda $\left(\mathbf{v}_{\mathbf{x}}, \mathbf{v}_{\mathbf{y}}\right)$ (4) menemukan persamaan waktu saat benda mencapai titik tertinggi, (5) menemukan persamaan posisi $(\mathbf{x}, \mathbf{y}),(6)$ menemukan persamaan waktu saat benda mencapai titik terjauh, (7) menemukan persamaan posisi saat benda mencapai titik tertinggi, (8) menemukan persamaan posisi saat benda mencapai titik terjauh pada gerak parabola di bidang miring tanpa gesekan udara. Mahasiswa ditugaskan menurunkan persamaan-persamaan fisis gerak secara matematis menggunakan pertanyaan penggiring dan kalimat informasi yang ada di modul.

3.1. Menggambarkan vektor gaya, percepatan, dan kecepatan di posisi tertentu benda yang bergerak parabola di bidang miring tanpa gesekan udara.

Untuk menggambarkan vektor, diberikan gambar sebuah benda yang dilemparkan dari titik A pada sebuah bidang miring dengan kecepatan awal vo seperti pada Gambar 1.

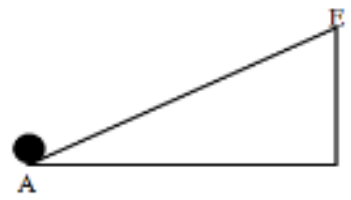

Gambar.1 : Gambar bidang miring sebagai lintasan gerak parabola
Mahasiswa ditugaskan untuk menggambarkan lintasan gerak benda jika gesekan udara diabaikan. Selanjutnya mahasiswa ditugaskan menggambarkan vektor gaya di titik A dengan menggiring mereka memikirkan apa saja gaya-gaya yang dialami benda dan ke mana arahnya pada sumbu horizontal ( $x$ ) dan sumbu vertikal (y). Setelah itu mahasiswa ditugaskan menggambarkan vektor percepatan di titik A dengan menggiring mereka untuk mempertimbangkan bagaimana gambar komponen vektor percepatan pada sumbu horizontal (x) dan sumbu vertikal (y) berdasarkan Hukum II Newton. Kemudian mahasiswa ditugaskan untuk menggambarkan komponen-komponen vektor $v_{0}$ pada benda.

Berdasarkan data dari lembar observasi Tabel 1 poin 3a-c diperoleh hasil bahwa semua responden dapat menggambarkan vektor gaya, vektor percepatan, dan vektor kecepatan sesuai tahapan yang dijelaskan pada modul walaupun ada dua responden yang salah dalam menggambarkan vektor percepatan (Tabel 1 poin $3 \mathrm{~b}$ ). Berdasarkan wawancara dengan responden, responden mengerti petunjuk atau langkah-langkah yang terdapat pada modul hanya saja responden lupa materi dan lupa dalam menggambarkan arah panah vektor, seperti Gambar 2.

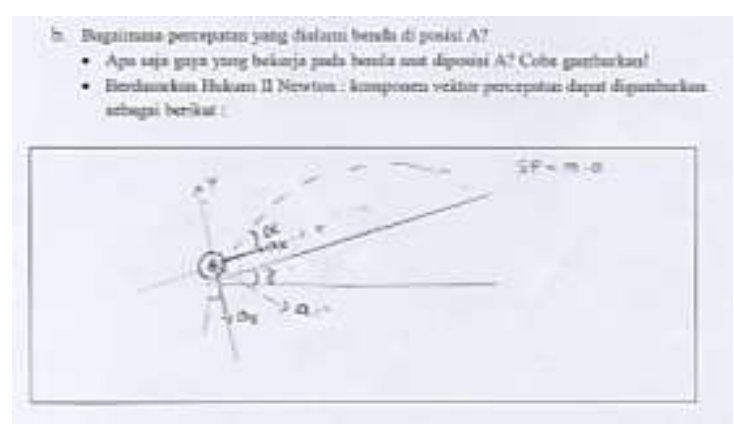

Gambar 2. Jawaban salah dari responden saat mengerjakan modul pada bagian menggambar vektor percepatan.

Hal ini berarti pertanyaan-pertanyaan penggiring pada modul dapat dipahami oleh mahasiswa dan efektif digunakan untuk menuntun mahasiswa untuk menggambarkan vektor gaya, vektor percepatan, dan vektor kecepatan benda yang bergerak parabola di bidang miring tanpa gesekan udara pada posisi tertentu. 
Volume 12 Nomor 1, Bulan April, Tahun 2019, pp: 9 - 19

Available online at: http://jurnal.umpwr.ac.id/index.php/radiasi p-ISSN: $\underline{2302-6111}$ e-ISSN: $\underline{2549-0826}$

3.2. Menemukan persamaan percepatan benda yang bergerak parabola di bidang miring tanpa gesekan udara.

Untuk mendapatkan persamaan percepatan benda, mahasiswa digiring secara bertahap dengan terlebih dahulu menanyakan Hukum II Newton [9] yaitu

$$
\sum \overrightarrow{\mathbf{F}}=m \cdot \overrightarrow{\mathbf{a}}
$$

sebagai dasar untuk menemukan resultan gaya yang bekerja pada benda, menanyakan gaya apa saja yang bekerja pada benda, dan bagaimana persamaan umum percepatan benda. Setelah itu mahasiswa diminta untuk menyelesaikan persamaan matematisnya agar mendapatkan hasil persamaan komponen vektor percepatan pada sumbu x [8][12]

$$
\overrightarrow{\mathbf{a}}_{\mathbf{x}}=g_{x}=-g \sin \gamma
$$

dan komponen vektor percepatan pada sumbu y [8][12]

$$
\overrightarrow{\mathbf{a}}_{\mathbf{y}}=g_{y}=-g \cos \gamma
$$

Responden dapat menjawab konsep Hukum II Newton, gaya-gaya yang bekerja pada benda, dan menemukan persamaan komponen vektor percepatan pada sumbu $x$ dan y. Dari tiga responden, didapatkan ada dua responden yang salah dalam menjawab persamaan komponen vektor percepatan pada sumbu $x$ dan $y$ sehingga menyebabkan kesalahan penulisan notasi vektor percepatan seperti pada Gambar 3.

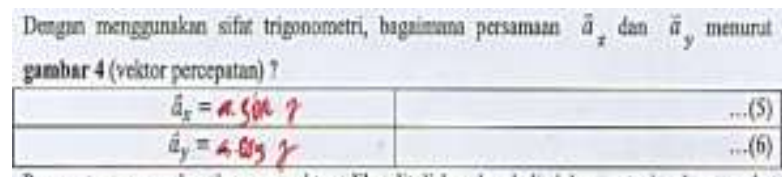

Pecegotan menspaka besanan veddor. Jika dralishan kembali dilam sotaci vektor, maka

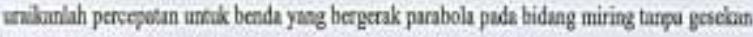

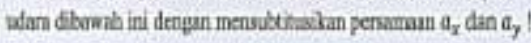

\begin{tabular}{|c|c|}
\hline$\vec{a}=a_{x} \hat{i}+a_{y} \hat{j} \quad x$ & \\
\hline$\hat{a}=. \Delta y+y+a \cos y$ & \\
\hline
\end{tabular}

Gambar 3. Jawaban salah dari responden saat menurunkan persamaan percepatan.

Berdasarkan hasil wawancara dengan responden, responden salah menurunkan persamaan karena tidak memberi tanda negatif pada komponen vektor percepatan pada sumbu $\mathrm{x}$ dan komponen vektor percepatan pada sumbu y sehingga membuat penulisan vektor percepatan tidak tepat. Persamaan komponen vektor percepatan yang didapatkan tidak sesuai dengan persamaan yang diinginkan, yaitu persamaan komponen vektor percepatan pada sumbu x [8][12] adalah

$$
\overrightarrow{\mathbf{a}}_{\mathbf{x}}=g_{x}=-g \sin \gamma
$$

dan persamaan komponen vektor percepatan pada sumbu y [8][12] adalah

$$
\overrightarrow{\mathbf{a}}_{\mathbf{y}}=g_{y}=-g \cos \gamma
$$

Pada bagian ini sebaiknya diperbaiki dengan pemberian kalimat informasi tambahan tentang $(+)$ dan (-) pada sumbu $x$ dan y agar responden tidak keliru.

3.3. Menemukan persamaan kecepatan benda yang bergerak parabola di bidang miring tanpa gesekan udara.

Pada bagian ini, supaya responden menemukan persamaan kecepatan benda yang bergerak parabola di bidang miring tanpa gesekan udara diberikan kalimat informasi bahwa dari persamaan percepatan yang diperoleh berdasarkan gambar vektor percepatan pada bagian kedua yaitu komponen vektor percepatan pada sumbu $\times\left(\overrightarrow{\mathbf{a}}_{\mathbf{x}}\right)$ dan komponen vektor percepatan pada sumbu y $\left(\overrightarrow{\mathbf{a}}_{\mathbf{y}}\right)$, benda mengalami peristiwa gerak lurus berubah beraturan (GLBB). Responden diminta untuk menemukan persamaan kecepatan berdasarkan gambar vektor kecepatan yang sudah diperoleh pada tahap sebelumnya. Semua responden dapat menemukan persamaan kecepatan benda yang bergerak parabola pada bidang miring tanpa gesekan udara.

Komponen vektor kecepatan pada sumbu $\mathrm{x}$, komponen vektor kecepatan pada sumbu y, dan menuliskan notasi vektor kecepatan (2) dengan benar melalui kalimat penggiring yang terdapat pada modul. Hal ini berarti kalimat yang ada di dalam modul untuk mencari persamaan kecepatan dapat dipahami dan dapat dikatakan efektif untuk menggiring menemukan persamaan kecepatan pada benda yang bergerak parabola di bidang miring tanpa gesekan udara. 
3.4. Menemukan persamaan waktu saat benda yang bergerak parabola di bidang miring tanpa gesekan udara mencapai titik tertinggi.

Pada bagian ini responden dituntun untuk menemukan persamaan waktu saat benda bergerak parabola pada bidang miring tanpa gesekan udara mencapai titik tertinggi dengan kalimat informasi bahwa berdasarkan gambar vektor kecepatan yang sudah didapatkan pada bagian sebelumnya, saat benda mencapai ketinggian maksimum benda tersebut akan berhenti sesaat, itu artinya benda tidak memiliki komponen kecepatan pada sumbu y atau $v_{\mathrm{y}}=0$ [12][13]. Selanjutnya dengan menggunakan persamaan (1.5) responden diminta untuk mensubstitusikan komponen $\mathrm{v}_{0 \mathrm{y}}$ dan menyelesaikan persamaan matematisnya untuk memperoleh hasil akhir berupa persamaan waktu saat benda mencapai titik tertinggi. Semua responden dapat menemukan persamaan waktu benda saat mencapai titik tertinggi dengan benar melalui bantuan pertanyaan penggiring yang terdapat pada modul. Hal ini berarti pertanyaan penggiring dan kalimat informasi yang diberikan dapat dikatakan efektif dalam menggiring menemukan persamaan waktu saat benda mencapai tititk tertinggi yaitu :

$$
t_{t}=\frac{v_{o} \sin \alpha}{g \cos \gamma}
$$

3.5. Menemukan persamaan posisi benda yang bergerak parabola di bidang miring tanpa gesekan udara secara umum.

Responden diberikan informasi untuk mencari persamaan komponen vektor posisi benda pada sumbu $\mathrm{x}$ adalah

$$
x=v_{\text {ox }} t+1 / 2 a_{x t^{2}}
$$

dan komponen vektor posisi benda pada sumbu y adalah

$$
y=v_{\text {oy }} t+1 / 2 a_{y t^{2}}
$$

kemudian responden diminta untuk mensubstitusikan persamaan (1) ke persamaan yang sudah diinformasikan. Selanjutnya responden diminta untuk menyelesaikan persamaan matematisnya untuk memperoleh hasil akhir yaitu persamaan komponen vektor posisi benda pada arah $\mathrm{x}$ dan arah $\mathrm{y}$ di bidang miring tanpa gesekan udara.
Responden dapat menemukan persamaan komponen vektor posisi benda pada arah $\mathrm{x}$ :

$$
x=v_{\text {ox }} t-1 / 2 g \sin \gamma t^{2}
$$

dan persamaan komponen vektor posisi benda pada arah y:

$$
y=v_{\text {oy }} t-1 / 2 g \sin \gamma t^{2}
$$

secara umum yang bergerak parabola di bidang miring tanpa gesekan udara dengan benar melalui bantuan kalimat penggiring yang pada modul. Hal ini berarti pertanyaan penggiring dan kalimat informasi yang terdapat di dalam modul dapat dikatakan efektif untuk menuntun mahasiswa menemukan persamaan umum posisi benda yang bergerak parabola pada bidang miring tanpa gesekan udara.

3.6. Menemukan persamaan waktu saat benda bergerak parabola di bidang miring tanpa gesekan udara mencapai titik terjauh $\left(\mathbf{t}_{\mathbf{j}}\right)$.

Pada bagian ini responden diminta untuk menemukan persamaan waktu saat benda yang bergerak parabola di bidang miring tanpa gesekan mencapai titik terjauh $\left(t_{j}\right)$. Responden diinformasikan bahwa ketika benda mencapai titik terjauh, koordinat y pada koordinat Cartesius adalah nol sehingga $y_{j}=0$ [8]. Responden diminta untuk menyelesaikan persamaan yang diinformasikan yaitu

$$
y=v_{\text {oy }}-1 / 2 a t^{2}
$$

dengan mensubstitusikan persamaan (2) dan menyelesaikan secara matematis sehingga diperoleh hasil akhir

$$
t_{j}=\frac{2 v_{o} \sin \beta}{g \cos \alpha}
$$

Semua responden dapat menemukan persamaan waktu ketika benda bergerak parabola di bidang miring tanpa gesekan udara mencapai titik terjauh dengan benar. Hal ini berarti kalimat penggiring dan informasi yang terdapat pada modul dapat dikatakan efektif untuk menuntun mahasiswa dalam menemukan persamaan waktu ketika benda bergerak parabola di bidang miring tanpa gesekan udara mencapai titik terjauh $\left(t_{j}\right)$. 
3.7. Menemukan Persamaan Posisi Saat Benda Bergerak Parabola di Bidang Miring Tanpa Gesekan Udara Mencapai Titik Tertinggi $\left(\mathbf{t}_{\mathbf{t}}\right)$.

Pada bagian ini responden diminta untuk menemukan persamaan posisi saat benda bergerak parabola di bidang miring tanpa gesekan udara mencapai titik tertinggi $t_{t}$ dengan pemberian persamaan

$$
x=v_{0} \cos \theta\left(t_{t}\right)-1 / 2(g \sin \theta)\left(t_{t}\right)^{2}
$$

untuk komponen vektor posisi pada sumbu $\mathrm{x}$ saat benda mencapai titik tertinggi. Responden diminta untuk menyelesaikan penurunan secara matematis dengan mensubstitusikan persamaan (4). Semua responden dapat menemukan persamaan posisi benda saat bergerak di bidang miring tanpa gesekan udara mencapai titik tertinggi pada arah sumbu $x$ sebagai berikut :

$x=\frac{v_{o}{ }^{2} \sin \alpha}{2 g \cos ^{2} \gamma}(2 \cos \gamma \cdot \cos \alpha-\sin \gamma \cdot \sin \alpha)$

dan persamaan komponen vektor posisi pada sumbu y sebagai berikut :

$$
y=\frac{v_{o}^{2} \sin ^{2} \alpha}{2 g \cos \gamma}
$$

Hal ini berarti kalimat penggiring dan informasi yang terdapat di dalam modul dapat dikatakan efektif untuk menuntun mahasiswa untuk menemukan persamaan posisi benda bergerak parabola di bidang miring tanpa gesekan udara mencapai titik tertinggi $\left(t_{\mathrm{t}}\right)$.
3.8. Menemukan Persamaan Posisi Saat Benda Yang Bergerak Parabola di Bidang Miring Tanpa Gesekan Udara Mencapai Titik Terjauh.

Pada bagian ini responden diminta untuk menemukan persamaan posisi saat benda bergerak parabola di bidang miring tanpa gesekan udara mencapai titik terjauh $\left(t_{j}\right)$ dengan pemberian persamaan

$$
x=v_{o} \cos \alpha\left(t_{j}\right)-\frac{1}{2}(g \sin \gamma)\left(t_{j}\right)^{2}
$$

untuk posisi pada sumbu $x$ saat benda mencapai titik tertinggi. Responden diminta untuk menyelesaikan penurunan matematis dengan mensubstitusikan persamaan (6). Pada saat benda jatuh mencapai tanah, jaraknya maksimum dan ketinggian benda saat itu pada sumbu y $=0$ [9]. Semua responden dapat menemukan persamaan komponen vektor posisi benda saat bergerak parabola di bidang miring tanpa gesekan udara mencapai titik tertinggi pada arah sumbu x yaitu

$$
y=\frac{2 v_{o}^{2} \sin \alpha}{2 g \cos \gamma} \cos (\alpha+\gamma)
$$

Hal ini berarti kalimat penggiring dan kalimat informasi yang terdapat di dalam modul dapat dikatakan efektif dalam menuntun mahasiswa untuk menemukan persamaan posisi benda bergerak parabola di bidang miring tanpa gesekan udara mencapai titik tertinggi $\left(t_{\mathrm{t}}\right)$.

Tabel 1. Hasil pengamatan observer di lembar observasi.

\begin{tabular}{clccc}
\hline \multirow{2}{*}{ No } & \multicolumn{1}{c}{ Kegiatan } & \multicolumn{3}{c}{ Responden } \\
\cline { 2 - 4 } & \multicolumn{1}{c}{$\mathbf{1}$} & $\mathbf{2}$ & $\mathbf{3}$ \\
\hline 1 & Mahasiswa mengikuti langkah-langkah sesuai modul. & $100 \%$ & $100 \%$ & $100 \%$ \\
2 & $\begin{array}{l}\text { Mahasiswa tidak bertanya kepada observer mengenai kejelasan modul } \\
\text { lebih dari 5 kali. }\end{array}$ & $100 \%$ & $100 \%$ & $100 \%$ \\
3 & $\begin{array}{l}\text { Mahasiswa dapat menggambarkan vektor-vektor besaran fisis pada } \\
\text { benda di titik tertentu pada gerak parabola di bidang miring tanpa } \\
\text { gesekan udara. }\end{array}$ & & \\
a. Menggambarkan vektor gaya pada titik tertentu. & $100 \%$ & $100 \%$ & $100 \%$ \\
b. Menggambarkan vektor percepatan pada titik tertentu. & $100 \%$ & $0 \%$ & $0 \%$ \\
c. Menggambarkan vektor kecepatan pada titik tertentu. & $100 \%$ & $100 \%$ & $67 \%$
\end{tabular}


4 Mahasiswa dapat menemukan persamaan percepatan gerak parabola pada bidang miring tanpa gesekan udara pada bidang miring.

a. Menuliskan Hukum II Newton.

$\begin{array}{ccc}100 \% & 100 \% & 100 \% \\ 100 \% & 100 \% & 100 \% \\ 0 \% & 100 \% & 0 \% \\ 0 \% & 100 \% & 0 \% \\ 0 \% & 100 \% & 0 \%\end{array}$

5 Mahasiswa dapat menemukan persamaan kecepatan gerak parabola pada bidang miring tanpa gesekan udara.

a. Menemukan persamaan komponen vektor kecepatan pada sumbu x.

b. Menemukan persamaan komponen vektor kecepatan pada sumbu y .

$100 \%$

c. Menemukan persamaan vektor kecepatan.

$100 \% \quad 100 \% \quad 100 \%$

6 Mahasiswa dapat menemukan persamaan waktu saat benda bergerak parabola di bidang miring tanpa gesekan udara mencapai titik tertinggi.

$100 \% \quad 100 \% \quad 100 \%$

7 Mahasiswa dapat menemukan persamaan posisi benda yang bergerak parabola di bidang miring tanpa gesekan udara secara umum.

a. Menemukan persamaan komponen vektor posisi benda pada arah $\mathrm{x}$.

$100 \% \quad 100 \% \quad 100 \%$

b. Menemukan persamaan komponen vektor posisi benda pada arah y.

$100 \% \quad 100 \% \quad 100 \%$

c. Menuliskan notasi vektor posisi benda.

$100 \% \quad 100 \% \quad 100 \%$

8 Mahasiswa dapat menemukan persamaan waktu saat benda bergerak parabola di bidang miring tanpa gesekan udara mencapai titik terjauh.

$100 \% \quad 100 \% \quad 100 \%$

9 Mahasiswa dapat menemukan persamaan posisi saat benda bergerak parabola di bidang miring tanpa gesekan udara mencapai titik tertinggi. a. Menemukan persamaan komponen vektor posisi benda pada arah $\mathrm{x}$ saat benda mencapai titik tertinggi.

b. Mahasiswa dapat menemukan persamaan komponen vektor posisi benda pada arah y saat benda mencapai titik tertinggi.

c. Menuliskan notasi vektor posisi benda saat mencapai titik tertinggi.

10 Mahasiswa dapat menemukan persamaan posisi saat benda bergerak parabola di bidang miring tanpa gesekan udara mencapai titik terjauh. a. Menemukan persamaan komponen vektor posisi pada sumbu x saat benda mencapai titik terjauh.

$100 \% \quad 100 \% \quad 100 \%$

b. Menemukan persamaan komponen vektor posisi pada sumbu y saat benda mencapai titik terjauh.

$100 \% \quad 100 \% \quad 100 \%$

$100 \% \quad 100 \% \quad 100 \%$

$100 \% \quad 100 \% \quad 100 \%$

c. Menuliskan notasi vektor posisi benda saat mencapai titik terjauh. 
Tabel 2. Hasil tanggapan responden pada lembar kuesioner.

\begin{tabular}{|c|c|c|c|c|c|}
\hline \multirow{2}{*}{ No } & \multirow{2}{*}{ Pertanyaan } & \multicolumn{3}{|c|}{ Responden } & \multirow[t]{2}{*}{ Rata-rata } \\
\hline & & 1 & 2 & 3 & \\
\hline 1 & $\begin{array}{l}\text { Apakah anda antusias dalam melakukan pembelajaran } \\
\text { dengan menggunakan modul mandiri? }\end{array}$ & $75 \%$ & $100 \%$ & $100 \%$ & $92 \%$ \\
\hline 2 & $\begin{array}{l}\text { Apakah belajar dengan modul mandiri anda dapat memahami } \\
\text { gerak pabola pada bidang miring tanpa gesekan udara? }\end{array}$ & $100 \%$ & $100 \%$ & $75 \%$ & $92 \%$ \\
\hline 3 & $\begin{array}{l}\text { Apakah jenis huruf dan equation dalam modul pembelajaran } \\
\text { mandiri gerak parabola di bidang miring tanpa gesekan } \\
\text { udara? }\end{array}$ & $75 \%$ & $75 \%$ & $100 \%$ & $83 \%$ \\
\hline 4 & $\begin{array}{l}\text { Apakah modul pembelajaran mandiri memberikan informasi } \\
\text { dan langkah - langkah penjelasan dengan jelas? }\end{array}$ & $75 \%$ & $100 \%$ & $100 \%$ & $92 \%$ \\
\hline & Rata-rata persentase tanggapan positif responden. & & & & $90 \%$ \\
\hline
\end{tabular}

Tabel 1 dan Tabel 2 menunjukkan hasil observasi yang dilaksanakan oleh observer, diperoleh rerata persenatase tanggapan dari responden sebesar $90 \%$, sedangkan hasil evaluai oleh responden disajikan Tabel 3.

Tabel 3. Hasil evaluasi responden

\begin{tabular}{c|c}
\hline Responden & Nilai \\
\hline 1 & 70 \\
2 & 80 \\
3 & 75 \\
Rata-rata & 75 \\
\hline
\end{tabular}

Berdasarkan Tabel 1, dari lembar observasi tampak bahwa responden dapat mengerjakan $88 \%$ langkah di modul, artinya semua responden dapat mengikuti/ mengerjakan lebih dari $70 \%$ langkah di modul pembelajaran mandiri dengan benar sehingga modul ini dapat dikatakan efektif membantu mahasiswa mempelajari materi gerak parabola pada bidang miring tanpa gesekan udara. Hal tersebut sejalan dengan [6], namun perlu ditambahkan pertanyaan penggiring atau informasi tambahan pada poin 3b, 4c, 4d, dan 4e. Dari Tabel 2 diperoleh data bahwa ketiga responden memberi respon positif sebesar rata-rata 90\% untuk semua pertanyaan di lembar kuesioner. Hal ini berarti modul pembelajaran mandiri yang dibuat dapat membantu mahasiswa mempelajari materi. Dari hasil evaluasi ketiga responden pada Tabel 3, semua responden mendapatkan nilai di atas 70, yaitu rata-rata 75 sehingga modul ini dapat dikatakan efektif membantu mahasiswa memahami materi. Dengan demikian, semua kriteria keberhasilan tercapai.

\section{KESIMPULAN}

Berdasarkan hasil penelitian yang sudah dilakukan, modul pembelajaran mandiri tentang gerak parabola pada bidang miring tanpa gesekan udara yang dibuat efektif membantu mahasiswa memahami gerak parabola pada bidang miring tanpa gesekan udara. Penelitian lebih lanjut dapat dilakukan dengan membuat simulasi gerak parabola di bidang miring tanpa gesekan udara.

\section{DAFTAR PUSTAKA}

[1] Purwadi and Ishafit, "Pemodelan Gerak Parabola yang Dipengaruhi Seretan serta Spin Efek Magnus Bola dengan Program Modellus dan Excell," JRKPF UAD, vol. 1, no. 1, pp. 11-18, Apr. 2014.

[2] R. Chandra Wijaya, D. M, and Kamid, "Pengembangan Media Pembelajaran Fisika Projectile Launcher sebagai Alat Praktikum Fisika pada Materi Gerak 
Parabola Fisika Kelas XI IPA," Edu-Sains, vol. 3, no. 2, pp. 47-56, Jul. 2014.

[3] S. Ho, S. Foong, C. Lim, C. Lim, K. Lin, and L. Kuppan, "Projectile motion on an inclined misty surface: I. Capturing and analysing the trajectory," Phys. Educ., vol. 44, no. 3, p. 253, 2009.

[4] M. Dinavalentine, D. Natalia Sudjito, and D. Noviandini, J. Pros. Nas. Quantum 2016 Program Studi Pendidik. Fis. Univ. Ahmad Dahlan, pp. 91-104, 2016.

[5] N. H. Astuti, D. Natalia Sudjito, and D. Noviandini, "Penggunaan Diagram Venn untuk Analisa Level Kognitif Mahasiswa Berdasarkan Taksonomi Bloom pada Pengembangan Modul Praktikum Mandiri Tentang Pembiasan Cahaya," J. Sci. Sci. Educ., vol. 2, no. 1, pp. 21-28, Mei 2018.

[6] D. N. Sudjito, "Desain Modul Pembelajaran Mandiri tentang Gerak Parabola pada Bidang Miring dengan Gesekan Udara," J. Penelit. Pembelajaran Fis., vol. 10, no. 1, pp. 10-21, 2019.

[7] L. Karanggulimu, D. Natalia Sudjito, and D. Noviandini, "Desain Modul Praktikum Mandiri Tentang Gerak Parabola Menggunakan Simulasi Phet"Projectile Motion"," Semin. Nas. Pendidik. Sains Dan Teknol. Fak. Mat. Dan Ilmu Pengetah. Alam Univ. Muhammadiyah Semarang, pp. 216226, 2017.
[8] P. A, Tipler and G. Mosca, Physics For Scientists and Engineers, Sixth Edition. W.H.Freeman, 2007.

[9] D. Halliday, R. Resnick, and Walker Jearl, Fundamental Of Physics, 7th extended edition, 7th ed. Jakarta: ERLANGGA, 2010.

[10] G. Muruganantham, "Developing Of Econtent Package By Using ADDIE Model," Int. J. Appl. Res., vol. 1, no. 3, pp. 52-54, 2015.

[11] I. M. Tegeh and I. M. Kirna, "Pengembangan Bahan Ajar Metode Penelitian Pendidikan Dengan Addie Model," J. IKA Univ. Pendidik. Ganesa, vol. 11, no. 1, pp. 12-26, Mar. 2013.

[12] Trishna, Super Course In Physics Mechanics I For The IIT-JEE, vol. 1. Pearson Education, 2012.

[13] U. Yahdi, Pengantar Fisika Mekanika, 1st ed. 1996. 
RADIASI: Jurnal Berkala Pendidikan Fisika

Volume 12 Nomor 1, Bulan April, Tahun 2019, pp: 9 - 19 Available online at: http://jurnal.umpwr.ac.id/index.php/radiasi p-ISSN: $\underline{2302-6111}$ e-ISSN: 2549-0826 